\title{
EPIDEMIOLOGIA DOS PACIENTES COM HIV/AIDS ATENDIDOS EM UM CENTRO DE REFERÊNCIA EM DOENÇAS INFECCIOSAS
}

\author{
Epidemiology of HIV/AIDS Patients Treated at a Referral Center for Infectious Diseases
}

\author{
Samuel da Silva Gomes ${ }^{1}$
}

Letícia de Melo Mota ${ }^{2}$

\begin{abstract}
Resumo: A infecção pelo vírus HIV e sua forma sindrômica manifestada na AIDS são um grave problema de saúde pública, que afeta populações em diferentes estratos sociais, com manifestações clínicas e sistêmicas inversamente proporcionais à contagem de Linfócitos $\mathrm{T}$ CD4+. Objetivo: Avaliar dados epidemiológicos em um centro de referência para tratamento de paciente vivendo com HIV/AIDS. Método: Trata-se de um estudo descritivo retrospectivo, baseado na coleta de dados feita através da revisão dos prontuários dos pacientes ativos, em seguimento ambulatorial regular, sobre a população de portadores de HIV/AIDS atendidos em um centro de referência em Montes Claros - MG. Resultados: Verificou-se, do total de pacientes avaliados que, quanto à terapia antirretroviral (TARV), 94,2\% estava em uso de TARV; que $66 \%$ dos pacientes possuíam carga viral indetectável e que as doenças oportunistas apresentadas por portadores de HIV/AIDS foram documentadas em 158 pacientes (51\% do total de pacientes), sendo a pneumocistose a condição mais prevalente. Conclusão: A taxa de pacientes sem TARV alerta para uma revisão desses no intuito de iniciar a introdução de terapia antirretroviral o mais precoce possível, bem como identificar os esquemas antirretrovirais utilizados e adequá-los de acordo com as novas recomendações.
\end{abstract}

Palavras-Chave: Epidemiologia; Doenças infecciosas; HIV; Aids; Terapia Antirretroviral;

Abstract: HIV infection and its syndromic form manifested in AIDS are a serious public health problem that affects populations in different social strata, with clinical and systemic

\footnotetext{
${ }^{1}$ Médico pela Universidade Estadual de Montes Claros (UNIMONTES). Montes Claros/MG-Brasil. $\triangle$ samuelgomesi@icloud.com_- https://orcid.org/0000-0003-0589-0885.

${ }^{2}$ Médica pela Universidade Federal de Uberlândia (UFU) - Uberlândia/MG - Brasil. Doutorado em Clínica Médica pela Faculdade de Medicina de Ribeirão Preto (FMRP-USP) - Ribeirão Preto/SP Brasil. $\triangle$ infectusdi@gmail.com. $\$$ https://orcid.org/0000-0002-5647-8244.
}

Recebido em Aceito em Publicado em

02/09/2021 22/10/2021 09/11/2021


manifestations inversely proportional to the CD4+ T lymphocyte count. Objective: Evaluate epidemiological data in a referral center for the treatment of patients living with HIV/AIDS. Method: This is a retrospective descriptive study, based on data collection carried out through a review of the medical records of active patients, in regular outpatient follow-up, on the population of HIV/AIDS patients cared for at a reference center in Montes Claros - MG Results: It was found that, from the total number of patients evaluated, regarding antiretroviral therapy (ART), 94.2\% were using ART; that $66 \%$ of patients had an undetectable viral load and that opportunistic diseases presented by HIV/AIDS carriers were documented in 158 patients (51\% of the total patients), with pneumocystosis being the most prevalent condition. Conclusion: The rate of patients without ART calls for a review of these in order to start the introduction of antiretroviral therapy as early as possible, as well as to identify the antiretroviral regimens used and adapt them in accordance with the new recommendations.

Keywords: Epidemiology; Infectious diseases; HIV; Aids; Antiretroviral Therapy;

\section{INTRODUÇÃO}

A síndrome da imunodeficiência humana (AIDS), causada pelo vírus da imunodeficiência humana (HIV), à época de seu reconhecimento, em 1981, nos EUA, chamou atenção para as frequentes e graves infecções oportunistas presentes principalmente em homens homossexuais, fato esse que tornou a epidemia estigmatizada e rodeada de preconceitos, inclusive no meio científico ${ }^{1}$.

Por muito tempo, especulou-se a sobre os mecanismos desta doença, pelo fato de não se saber, à época, seu agente etiológico. Porém, havia um consenso: a doença tinha como fisiopatologia básica a imunossupressão, haja vista as inúmeras doenças oportunistas, como a pneumonia por Pneumocystis jirovecii e o sarcoma de Kaposi. O evoluir da doença, trouxe indícios de sua etiologia viral e da sua transmissão por fluidos corpóreos, como a presença da síndrome em crianças e hemofílicos hemotransfundidos e a infecção em mulheres e em usuários de drogas injetáveis, o que evidenciou a expansão da epidemia a outros segmentos populacionais que não os homossexuais ${ }^{2}$

Com a descoberta do HIV, em 1983, pode-se aventar seu diagnóstico, com desenvolvimento de testes sorológicos e métodos terapêuticos. A instituição da terapia antirretroviral (TARV) gratuita no Brasil permitiu a redução em 50\% da mortalidade por AIDS e o aumento em $80 \%$ do tratamento para doenças oportunistas, com sensível melhora na qualidade de vida dos pacientes ${ }^{1-3}$. 
Hoje, o quadro epidemiológico da AIDS no Brasil é fruto de profundas quebras de paradigmas anteriores. A epidemia deixou de ser mais prevalente em homossexuais e disseminou-se progressivamente entre mulheres, por meio de relações heterossexuais sem proteção ${ }^{4}$. Os homossexuais chegaram a perfazer $50 \%$ dos casos de HIV na década de 80, e, na década de 90, a taxa se estabilizou por volta de 18\%. Em 2012, no Brasil, dos pacientes diagnosticados com AIDS do sexo masculino, 32,0\% eram homossexuais, 9,4\% bissexuais, $52,7 \%$ heterossexuais ${ }^{5}$.

Estima-se que 718 mil pessoas vivam com HIV/AIDS no Brasil, o que corresponde à prevalência, na população, de $0,4 \%$. O número de portadores virgens de tratamento que chegam ao serviço com CD4 superior a 500 células por $\mathrm{mm}^{3}$ aumentou (28,9\% em 2003 para quase $37 \%$ em 2012). Além disso, 74\% dos portadores do vírus estão vinculados a um serviço de saúde, sendo monitorados por meio de carga viral e contagem de células CD4 ou estando em uso de Terapia Antirretroviral (TARV). Desses, 44\% estão em uso de TARV. O número de pessoas vivendo com HIV/AIDS (PVHA) em uso de TARV, inclusive, mais que dobrou em 10 anos (125 mil em 2002 para 313 mil em 2012). ${ }^{5}$

As taxas mundiais e nacionais apresentam um contexto geral; entretanto é importante que se conheçam os dados de cada serviço. As variantes apresentadas e seus resultados são fruto das condições regionais, socioeconômicas e culturais, nas quais a população está inserida. Portanto, o objetivo do estudo é conhecer o perfil epidemiológico; clínico e de tratamento dos pacientes ativos portadores de HIV/AIDS atendidos no Centro de Atendimento Especializado Tancredo Neves (CAETAN) da Universidade Estadual de Montes Claros (Unimontes).

\section{MÉTODO}

Trata-se de um estudo descritivo retrospectivo sobre a população de portadores de HIV/AIDS atendidos no Centro de Atendimento Especializado Tancredo Neves (CAETAN) em Montes Claros - MG e ativos no período de janeiro a março de 2014. Atualmente, os dois serviços especializados disponíveis na cidade; ambulatório do CAETAN e o Centro de Testagem e Aconselhamento (CTA) /Serviço de Atendimento Especializado (SAE) abrangem pacientes de Montes Claros e toda Macrorregião. O ambulatório de atendimento aos portadores no CAETAN é o objeto do estudo. 
A coleta dos dados foi feita através da revisão dos prontuários dos pacientes ativos, em seguimento ambulatorial regular no período. Como critério de inclusão, foi definido que todos os pacientes soropositivos atendidos regularmente no serviço seriam incluídos no estudo; e de exclusão são aqueles que foram a óbito e aqueles cujo último retorno ocorreu há mais de um ano, assim caracterizado como abandono do tratamento. Os critérios de confirmação de casos de AIDS considerados foram os utilizados no atendimento do referido serviço e disposto pelo Ministério da Saúde, que são apresentados no manual Critério de Definição de Casos de AIDS em Adultos e Crianças ${ }^{8}$.

As variáveis compiladas nessa pesquisa foram divididas em áreas: 1) Sócio demográficas: Sexo; idade; procedência; estado civil e/ou presença ou não de parceiro fixo; 2) Tratamento: pacientes em tratamento ou não; quais esquemas de TARV utilizados; últimos resultados de carga viral e contagem de linfócitos TCD4 registrados até o momento da coleta de dados; 3) Coinfecções.

O estudo segue as regulamentações descritas na Resolução $\mathrm{N}^{\mathrm{o}} 466 / 12$ do Conselho Nacional de Saúde do Ministério da Saúde e se iniciou após ter sido apreciado e aprovado pelo Comitê de Ética em Pesquisa (CEP) da UNIMONTES mediante o Parecer Consubstanciado $N^{\circ}$ 2.341.966, além de seguir os padrões exigidos dentro da Declaração de Helsinki.

\section{RESULTADOS}

Variáveis sócio demográficas

Foram registrados no serviço de HIV-DST do CAETAN 307 pacientes ativos, 179 do sexo masculino (58\%) e 128 do sexo feminino (42\%). A idade média foi de 44,62 anos e mediana de 45 anos. Quanto ao estado civil, 137 (45\%) eram solteiros, 99 (32\%) casados, 25 (8\%) pacientes viúvos, 20 (6,5\%) amasiados, 23 (7,5\%) divorciados e três (1\%) não tiveram registro quanto ao estado civil (Tabela 1).

Tabela 1 - Características epidemiológicas dos indivíduos com diagnóstico de infecção pelo HIV em um Centro de Referência Montes Claros, Estado de Minas Gerais.

\begin{tabular}{lcc}
\hline & Variáveis & Pacientes $(\mathbf{n}=\mathbf{3 0 7})$ \\
\hline & Masculino & $58 \%(179)$ \\
\cline { 2 - 3 } Sexo & Feminino & $42 \%(128)$ \\
\hline
\end{tabular}




\begin{tabular}{ccc}
\hline & Solteiro & $45 \%(137)$ \\
\cline { 2 - 3 } Estado & Casado & $32 \%(99)$ \\
\cline { 2 - 3 } Civil & Viúvo & $8 \%(25)$ \\
\cline { 2 - 3 } & Amasiado & $7 \%(23)$ \\
\cline { 2 - 3 } Parceria & Divorciado & $1 \%(3)$ \\
\cline { 2 - 3 } Sexual & Com parceiro fixo & $39 \%(119)$ \\
\cline { 2 - 3 } & Sem parceiro Fixo & $60 \%(185)$ \\
\hline
\end{tabular}

Quanto à procedência, dos 307 pacientes, 123 (40\%) eram residentes de Montes Claros e $184(60 \%)$ são de outras cidades que compõem a Macrorregião Norte de Minas Gerais.

\section{Variáveis de Tratamento}

Os pacientes acompanhados no serviço se distribuíram quanto à forma de seguimento em: 91\% (279) com seguimento regular, 9\% (28) seguimento irregular. Quanto à terapia antirretroviral, 5\% (15) não estavam em uso, 94,2\% (292) usavam TARV e 0,3\% (1) possui dado não informado. Quanto à terapia usada na época do levantamento de dados, 25,5\% (78) dos pacientes mantinham esquema com Biovir ${ }^{\circledR}$ (AZT+3TC) + EFV; 16,5\% (51) com Biovir $^{\circledR}(\mathrm{AZT}+3 \mathrm{TC})+$ Kaletra $^{\circledR}(\mathrm{LPV} / \mathrm{r})$ e $16 \%$ (49) pacientes com TDF + 3TC + Kaletra $^{\circledR}(\mathrm{LPV} / \mathrm{r})$. Já o esquema de TDF + 3TC + EFV foi observado em 8\% (24) dos pacientes, enquanto TDF + 3TC + ATV/r em 5,8\% (19) dos pacientes, e Biovir ${ }^{\circledR}$ (AZT+3TC) + NVP foi prescrito para 5,3\% (18) dos pacientes. Esquemas com RAL / DRV / MRQ foram encontrados em $4 \%$ (12) pacientes e DDI foi verificada como uma das drogas do esquema em $3,5 \%$ (10) dos pacientes. Apenas um paciente (0,32\%) manteve D4T no esquema, outros 1,3\% (quatro pacientes) fizeram uso do FPV e 1,96\% dos (seis) pacientes apresentavam uso de Biovir $^{\circledR}+$ ATV/r. Outras combinações como esquemas sem Ritonavir: Biovir ${ }^{\circledR}+$ ATV, TDF + 3TC + ATV foram incluídos em alguns esquemas não preconizados pela literatura, compreendendo um total de 27 esquemas terapêuticos, o que equivale a aproximadamente $9 \%$ dos clientes (Tabela 2). 
Tabela 2 - Tipos de TARV utilizadas pelos pacientes.

\begin{tabular}{|c|c|}
\hline Tipo de Esquema & Pacientes $(\mathrm{N}=307)$ \\
\hline Biovir ${ }^{\circledR}+\mathrm{EFV}$ & $25,5 \%(78)$ \\
\hline Biovir $\AA$ + Kaletra ${ }^{\circledR}$ & $16,5 \%(51)$ \\
\hline $\mathrm{TDF}+3 \mathrm{TC}+$ Kaletra ${ }^{\circledR}$ & $16 \%(49)$ \\
\hline $\mathrm{TDF}+3 \mathrm{TC}+\mathrm{EFV}$ & $8 \%(24)$ \\
\hline $\mathrm{TDF}+3 \mathrm{TC}+\mathrm{ATV} / \mathrm{r}$ & $5,8 \%(19)$ \\
\hline Biovir ${ }^{\circledR}(\mathrm{AZT}+3 \mathrm{TC})+\mathrm{NVP}$ & $5,3 \%(18)$ \\
\hline Esquemas com RAL / DRV / MRQ & $4 \%(12)$ \\
\hline Esquema com FPV & $1,3 \%(4)$ \\
\hline Esquemas com DDI & $3,5 \%(10)$ \\
\hline Esquemas com D4T & $0,3 \%(1)$ \\
\hline Outros esquemas & $9 \%(27)$ \\
\hline Sem TARV & $4,5 \%(15)$ \\
\hline Sem informação & $0,3 \%(1)$ \\
\hline
\end{tabular}

Legenda: EFV (Efivarenz), TDF (Tenofovir), 3TC (Lamivudina), NVP (Nevirapina), DDI (Didanosina), d4T (Estavudina), RAL (Raltegravir), DRV (Darunavir), MRQ (Maraviroc), FPV (Fosamprenavir), ATV/r (Atazanavir + Ritonavir), Biovir ${ }^{\circledR}$ (Lamivudina + Zidovudina), Kaletra ${ }^{\circledR}$ (Liponavir + Ritonavir).

Referente aos exames de rotina preconizados para pacientes com diagnóstico recente, foram verificadas as solicitações de sorologias habituais e importantes no contexto regional e do ambulatório DST/HIV como sorologias para T. cruzi e Leishmaniose Visceral (L. chagasi). Apenas $36 \%$ dos pacientes (110) tiveram alguma dessas sorologias pesquisadas e registradas em prontuário, enquanto que 64\% dos pacientes (197) não as tiveram registradas. As sorologias para detecção de antígenos e anticorpos do vírus da Hepatite B foram as mais solicitadas no serviço: $25,5 \%$ dos pacientes (78) tinham documentação de 
solicitação dessas, sendo que um paciente foi diagnosticado com a doença e os outros 77 pacientes tiveram sorologia negativa. Quanto à Hepatite C, 71 pacientes foram investigados, sendo sete com sorologias positivas e 64, negativas. A investigação para Doença de Chagas foi realizada em 30 pacientes, sendo que três detectados como portadores da doença e 27 com sorologias negativas.

O perfil de carga viral e imunidade também foram verificados em todos os pacientes ativos. Cerca de 66\% (202) dos pacientes possuíam carga viral (CV) indetectável e 30\% (93) dos pacientes possuíam CV detectável, sendo que 4\% (12) dos pacientes não tiveram exames evidenciados no prontuário. Com relação à contagem de células T CD4+, $84 \%$ (259) dos pacientes apresentavam-se acima 200 cels $/ \mathrm{mm}^{3}$ e somente $13 \%$ (38) dos pacientes possuíam CD4+ abaixo de $200 \mathrm{cels} / \mathrm{mm}^{3}$. Dez pacientes (3\%) não possuíam exame de contagem de CD4+ (Tabela 3).

Tabela 3 - Avaliação do Tratamento: Valor de carga viral (CV) e contagem de células CD4+.

\begin{tabular}{|c|c|c|}
\hline \multicolumn{2}{|c|}{ Variável } & Pacientes $(\mathrm{N}=307)$ \\
\hline \multirow[t]{3}{*}{$\mathrm{CV}$} & CV Indetectável & $66 \%(202)$ \\
\hline & CV detectável & $30 \%(93)$ \\
\hline & Sem exames & $4 \%(12)$ \\
\hline \multirow{3}{*}{$\begin{array}{c}\text { Número de } \\
\text { células T CD4+ }\end{array}$} & $>200 \mathrm{cels} / \mathrm{mm}^{3}$ & $84 \%(259)$ \\
\hline & $<200 \mathrm{cels} / \mathrm{mm}^{3}$ & $13 \%(38)$ \\
\hline & Sem exames & $3 \%(10)$ \\
\hline
\end{tabular}

As doenças oportunistas apresentadas por portadores de HIV/AIDS foram documentadas em 51\% (158) dos pacientes. Esses tiveram pelo menos uma doença relacionada ao HIV e/ou doença oportunista. Foram diagnosticados pneumonia em 55 desses pacientes, condição mais prevalente entre os pacientes do serviço analisado, sendo que desses, nove foram consideradas Pneumocistose. Tuberculose (TB) pulmonar foi diagnosticada em 30 pacientes, assim como Herpes Zoster, em 25 pacientes. Neurotoxoplasmose foi vista em 22 pacientes, e Leishmaniose Visceral em 15 pacientes. Outros tipos de TB foram diagnosticados em 14 pacientes, a saber: TB pleural em sete pacientes, TB ganglionar em 6 pacientes, e TB ocular em 1 paciente. Monilíase esofágica acometeram quatro pacientes e Sarcoma de Kaposi 
desenvolveu-se em dois pacientes. Outras condições que se desenvolveram nos pacientes foram: sífilis secundária, em dois pacientes; infecção por HTLV, condiloma acuminado, histoplasmose disseminada e criptococose, todas presentes em 1 paciente cada. (Tabela 4)

Tabela 4 - Prevalência de infecções oportunistas em pacientes HIV seguidos no Ambulatório HIV/DST. Montes Claros, Minas Gerais. Brasil.

\begin{tabular}{ccc}
\hline Infecções oportunistas & Prevalência & \% \\
\hline Pneumonia (outras além da & 46 & $28,2 \%$ \\
causada por P.jirovecii) & 30 & $18,2 \%$ \\
\hline Tuberculose pulmonar & 9 & $6,8 \%$ \\
\hline Pneumocistose & 7 & $5,2 \%$ \\
\hline Tuberculose pleural & 6 & $4,6 \%$ \\
\hline Tuberculose ganglionar & 1 & $0,6 \%$ \\
\hline Tuberculose ocular & 25 & $15,6 \%$ \\
\hline Herpes Zoster & 22 & $13,6 \%$ \\
\hline Neurotoxoplasmose & 4 & $2,4 \%$ \\
\hline Moniliase esofagiana & 2 & $1,2 \%$ \\
\hline Sarcoma de Kaposi & 2 & $2,3 \%$ \\
\hline Sífilis secundaria & 1 & $0,6 \%$ \\
\hline HTLV & 1 & $0,6 \%$ \\
\hline Histoplasmose disseminada & $\mathbf{1 5 8}$ & $0,6 \%$ \\
\hline Criptococose & 1 & $0,6 \%$ \\
\hline Total & $100,0 \%$ \\
\hline
\end{tabular}

Legenda: HTLV (Human T-lymphotropic virus)

\section{DISCUSSÃO}

Segundo estimativas do Ministério da Saúde, a taxa de prevalência de pacientes soropositivos do país é de $0,4 \%$. Considerando a população média em Montes Claros de 400.000 (412.284 habitantes em 2010); estima-se que cerca de 1.600 pacientes estejam infectados. Assim, com a amostra total de 307 pacientes ativos em seguimento nesse serviço, corresponde a $0,03 \%$ da população que faz acompanhamento. Mesmo com a existência de outro serviço de referência para atendimento aos pacientes com HIV/AIDS na cidade, com número de pacientes estimado em cerca de 400, ainda assim, se mostra uma taxa de 
prevalência abaixo da esperada, denotando uma possível subnotificação ou escassez de diagnóstico. Esse dado argumenta ações de busca ativa de pacientes na comunidade.

O predomínio de homens, porém com importante número de mulheres infectadas numa relação de prevalência homem/mulher de 1,4 corrobora com a literatura, que nos informa uma prevalência de homens sobre mulheres. Quanto à faixa etária, também foi concordante a prevalência de pacientes adultos, com média etária próxima aos 40 anos ${ }^{9-11}$. Não foi possível estabelecer a relação entre soropositivos; grau de escolaridade e nível socioeconômico por falta de dados completos no prontuário.

Por outro lado, um estudo prévio, neste mesmo ambulatório, em 2007, contabilizou 457 pacientes em seguimento, 150 pacientes a mais que o encontrado por este estudo. Essa queda se justifica por evasão, transferência de pacientes e óbitos até o presente levantamento ${ }^{11}$.

Referente ao principal grupo de risco para a infecção, considerado como pacientes sem parceiro fixo, esse estudo documentou uma taxa de 60\%. Em um estudo realizado em 2011, verificou-se que os pacientes sem parceiro fixo compreenderam $35 \%$ do total analisado $^{11}$. Esse dado demonstra um aumento do número de pacientes soropositivos com parceria fixa ao longo do tempo no serviço. Acrescido às recomendações do Ministério da Saúde, fundamenta-se com esses dados a necessidade cada vez mais precoce e ampla de uso da terapia antirretroviral para os pacientes diagnosticados com HIV/AIDS.

Nos prontuários, não foram registrados, de forma considerável para fins científicos, dados como orientação sexual do paciente, prática sexual desprotegida e prática de coito anal receptivo, informações importantes para a análise dos fatores de risco que os pacientes estavam ou estão expostos e para realizar orientações quanto ao contágio de outros parceiros. Em um estudo realizado em 2010, no mesmo ambulatório, foi registrado que $84 \%$ (168 pacientes) eram heterossexuais, $10,5 \%$ (21 pacientes) eram homossexuais e 5,5\% (11 pacientes) eram bissexuais ${ }^{10}$.

O uso da terapia em 292 (95\%) pacientes nesse serviço supera as estatísticas liberadas pelo Ministério da Saúde que indica $44 \%$ das pessoas vivendo com HIV/AIDS em uso de TARV até $2012^{5}$. Entretanto, diante das perspectivas de tratamento apresentadas e ampliação das indicações, o percentual de pacientes em uso de TARV será maior estimado nos anos subsequentes. Salienta-se que, muitos desses pacientes considerados nas estatísticas 
do Ministério da Saúde não têm seguimento em serviço de atendimento ao portador de HIV ou estão em seguimento irregular. Já o grupo de pacientes analisados no presente estudo considera apenas aqueles pacientes com seguimento em nosso serviço de atendimento especializado. Em um estudo realizado no sul de Santa Catarina, em 2010, com metodologia semelhante, mostrou a cifra de $71,6 \%$ de pacientes em uso de TARV ${ }^{11}$. Estudos do CDC (Center for Disease Control), o MMP (Medical Monitoring Project), de 2011, também corrobora para uma taxa mais alta de uso de TARV em pacientes com seguimento médico, $83 \%^{13}$. Assim, segundo as atuais diretrizes do Ministério da Saúde sobre terapêutica que recomenda o início precoce de TARV, no momento do diagnóstico, torna esses pacientes ainda sem tratamento importantes candidatos para o início imediato da terapia ${ }^{14}$.

O esquema mais comumente utilizado foi $\mathrm{AZT}+3 \mathrm{TC}+\mathrm{EFV}$, seguido por AZT+3TC+LPV/r. Segundo as diretrizes do Ministério da Saúde ${ }^{18}$, são esquemas terapêuticos iniciais preconizados à época da coleta dos dados. Entretanto, cabe salientar que as indicações dos esquemas devem considerar as condições de morbidade de cada paciente e são modificadas de acordo com o surgimento de novas drogas com melhores barreiras genéticas, facilidade posológica e menos efeitos colaterais. Assim, segundo a mesma diretriz, a preferência pelo esquema $\mathrm{TDF}+3 \mathrm{TC}+\mathrm{EFV}$ dá-se pela posologia favorável, pela menor incidência de lipodistrofia e de desordens hematológicas, com o TDF, e pela supressão de replicação viral a longo prazo, pelo EFV. Porém, o principal motivo pelo qual o uso do Biovir + EFV foi o esquema terapêutico mais utilizado no serviço é a introdução dos mesmos previamente ao surgimento do TDF e recomendação atual. Ainda, com o advento da terapia combinada, foi possível rever e adequar os esquemas atuais com a introdução do TDF em substituição ao EFV ${ }^{14-15}$. Em 2017, uma atualização da diretriz para tratamento de HIV/AIDS alterou a primeira escolha para $\mathrm{TDF}+3 \mathrm{TC}+\mathrm{DTG}$.

A presença de esquemas com RAL, DRV e MRQ se justifica, segundo o Ministério da Saúde, com a presença de falha virológica e com resistência a, pelo menos, um antirretroviral de cada uma das três classes (ITRN, ITRNN e IP), detectada em genotipagem. Já o uso de FPV se justifica pela presença de contraindicação de LPV/r ${ }^{14}$.

Os valores de linfócitos TCD4 e carga viral são importantes critérios para avaliação de prognóstico e consequente sucesso do tratamento do HIV. Segundo diretrizes nacionais, o objetivo primordial do tratamento com antirretrovirais é tornar a CV indetectável, 
o que se alcançou em $202(66 \%)$ dos pacientes em estudos ${ }^{14}$. Em estudo realizado em Santa Catarina, cerca de $49 \%$ dos pacientes estavam com CV indetectável ${ }^{11}$. Nos dados no Ministério da Saúde, essa cifra ainda é menor: somente 33\% dos pacientes com AIDS têm CV indetectável (ou seja, menor que 40 cópias/ ml). O grupo de pacientes em uso de TARV apresentou-se $76 \%$ com CV indetectável ${ }^{7}$.

Apesar de a carga viral indetectável ser o parâmetro de resposta terapêutica, os valores de CD4 também são importantes para avaliação do paciente portador de HIV/AIDS, principalmente quanto ao prognóstico. Pacientes com CD4 acima de 500 células $/ \mathrm{mm}^{3}$ e carga viral indetectável atingem expectativa de vida semelhante à da população geral ${ }^{18}$. Em protocolos anteriores, o valor de CD4 ao diagnóstico era usado, em conjunto com outros critérios, para definir pelo início de TARV, sendo que era critério absoluto para início de terapêutica CD4 menor que $200^{7}$. Hoje, porém, é recomendado considerar início de TARV em todos os pacientes com HIV/AIDS. Logo foi detectado que 15 pacientes estão sem o uso de TARV e merecem avaliação para início imediato.

Referente às coinfecções, a taxa de investigação para outras doenças sexualmente transmissíveis concomitantes em pacientes com HIV/AIDS no ambulatório foi baixa. Segundo orientação do Ministério da Saúde, deve-se investigar todos os pacientes recém diagnosticados com solicitações de sorologias para hepatites virais, VDRL, IgG para Toxoplasma, HTLV I e II e sorologia para Doença de Chagas e Leishmaniose em áreas endêmicas ${ }^{18}$. Segundo a literatura, a prevalência de coinfecção HIV/HCV é de 3-4\% e, geralmente, tem relação com transfusões sanguíneas ${ }^{16,17}$. Já com relação à coinfecção HIV/HBV a literatura indica uma prevalência maior, por volta de $12 \%{ }^{17,18}$. Em nosso estudo, tais dados não se confirmaram, já que apenas um paciente $(1,2 \%$ dos pacientes com $\mathrm{Hbs} A g$ solicitados) teve o diagnóstico de Hepatite B confirmado dentre 78 pacientes investigados com sorologias, enquanto que $7(4,97 \%)$ pacientes tiveram sorologia para HCV positiva em 71 com sorologias solicitadas. Cabe ressaltar que a baixa taxa de coinfecção também se relaciona com uma baixa taxa de investigação o que dificulta análise dos dados em comparação com a literatura.

Com relação às infecções oportunistas, quase metade dos pacientes seguidos tiveram, em algum momento do seguimento, alguma infecção oportunista, com destaque para pneumonia de origem bacteriana, tuberculose pulmonar, herpes zoster e neurotoxoplasmose, 
dado esse concordante com um estudo do Paraná, que avaliou a prevalência de infecções oportunistas em pacientes com HIV/AIDS, destacando serem mais frequentes as pneumonias bacterianas como infecções oportunistas em pacientes com uso irregular de TARV ${ }^{3}$.

No estudo, 73,4\% (22) dos pacientes portadores TB pulmonar eram homens, enquanto 26,6\% (8) dos pacientes eram mulheres. A idade média de acometimento foi de 43,9 anos. O risco de um indivíduo não infectado com o HIV desenvolver TB varia de 5\% a 10\%, enquanto os portadores de HIV/AIDS têm um risco de 50\%. Quando se considera pacientes portadores de infecção lactente por Mycobacterium tuberculose o risco aumenta 20 vezes nos soropositivos quando comparado aos pacientes não portadores de HIV/AIDS ${ }^{6}$.

A prevalência de Leishmaniose Visceral diagnosticada nos pacientes seguidos por HIV/AIDS foi de 50\% (15 casos tratados) dentre os 30 pacientes admitidos no ano de 2013, sendo que 67\% são homens, dados semelhantes aos encontrados na literatura. A coinfecção LV/HIV torna o Calazar uma doença mais grave, de progressão mais rápida e uma má resposta ao tratamento ${ }^{18-20}$. Assim, por ser área endêmica de Leishmanioses, esperava-se uma taxa maior de pacientes testados com sorologias para essa doença.

A prevalência de neurotoxoplasmose em pacientes com HIV/AIDS foi de 7\% (22 pacientes), porcentagem próxima à encontrada na literatura. A prevalência de soropositividade foi de $80 \%$ do total de pacientes com testes realizados. Observou-se que $32 \%$ dos pacientes acometidos por essa infecção oportunista não faziam uso regular de HAART, $18,4 \%$ apresentaram contagem de linfócitos T CD4+ inferior a 200 céls $/ \mathrm{mm}^{3} 21$.

\section{CONCLUSÃO}

A ausência de dados referentes ao comportamento sexual dos pacientes limitou a análise de risco de transmissão. Já a taxa de pacientes sem TARV alerta para uma revisão desses no intuito de otimizar a introdução de terapia antirretroviral o mais precoce possível, e a evidência de pacientes com esquemas de antirretrovirais antigos ou modificados permite a busca e adequação dos mesmos às mudanças atuais. A baixa taxa de solicitação de sorologias de triagem de coinfecções motiva a padronização com protocolos de testes para pacientes recém-diagnosticados e a análise de distribuição de infecções oportunistas permite maior entendimento do perfil dos pacientes e pronta abordagem diagnóstica a suspeita. 


\section{REFERÊNCIAS}

1. BRITO, Ana Maria de et al. AIDS e infecção pelo HIV no Brasil: uma epidemia multifacetada. Revista da Sociedade Brasileira de Medicina Tropical [online]. 2001, v. 34, n. 2 [Acessado 1 Setembro 2021] , pp. 207-217.

2. VERAS, Renato Peixoto et al. Epidemiologia: contextos e pluralidade [online]. Rio de Janeiro: Editora FIOCRUZ. 1998;4:172p.

3. FAGUNDES, Vinicius Henrique Veraldo et al. Infecções Oportunistas em indivíduos com infecção pelo HIV e relação com uso de terapia antirretroviral. Acta Scientiarum Health Sciences. 2010;32(2):141-5.

4. ARAÚJO, Vera Lúcia Borges de et al. Características da Aids na terceira idade em um hospital de referência do Estado do Ceará, Brasil. Revista Brasileira de Epidemiologia [online]. 2007, v. 10, n. 4 [Acessado 1 Setembro 2021] , pp. 544-554.

5. BRASIL. Ministério da Saúde. Secretária de Vigilância Saúde. Programa Nacional de DST e AIDS. Boletim Epidemiológico - AIDS e DST.2013;2.

6. BRUNELLO, Maria Eugênia Firmino et al. Áreas de vulnerabilidade para co-infecção HIV-aids/TB em Ribeirão Preto, SP. Revista de Saúde Pública [online]. 2011, v. 45, n. 3 [Acessado 1 Setembro 2021] , pp. 556-563.

7. BRASIL. Ministério da Saúde. Secretaria de Vigilância em Saúde. Programa Nacional de DST e Aids. Critérios de definição de casos de aids em adultos e crianças./ Ministério da Saúde, Secretaria de Vigilância em Saúde, Programa Nacional de DST e Aids. Brasília : Ministério da Saúde, 2003.

8. PIERRE, Flávia Meneguetti, LAURENTI, Ruy. HIV/AIDS: Perfil epidemiológico de adultos internados em hospital universitário. Cienc Cuid Saude. 2012; 11: 144-152.

9. RODRIGUES NETO, João Felício et al. Perfil de adultos infectados pelo vírus da imunodeficiência humana (HIV) em ambulatório de referência em doenças sexualmente transmissíveis no norte de Minas Gerais. Rev. Med. Minas Gerais. 2010;20(1):22-29.

10. SCHUELTER-TREVISOL, Fabiana et al . Perfil epidemiológico dos pacientes com HIV atendidos no sul do Estado de Santa Catarina, Brasil, em 2010. Epidemiol. Serv. Saúde, Brasília, v. 22, n. 1, p. 87-94, mar. 2013.

11. PEREIRA, João Alves et al. Infecção pelo hiv e aids em município do norte de Minas Gerais. Rev. APS. 2011;14(1).

12. BLAIR, Janet et al. Clinical and behavioral characteristics of adults receiving medical care for HIV infection - Medical 243 Monitoring Project, United States, 2007. MMWR Surveill Summ. 2011; 60(11):1-20. 
13. BRASIL. Ministério da Saúde. Secretaria de Vigilância em Saúde. Departamento de DST, Aids e Hepatites Virais. Protocolo clinico e diretrizes terapêuticas para manejo da infecção pelo HIV em adultos. Brasília. 2013.

14. BRASIL. Ministério da Saúde. Secretaria de Vigilância em Saúde. Departamento de DST, Aids e Hepatites Virais. Adesão ao tratamento antirretroviral no Brasil: coletânea de estudos do Projeto Atar: Projeto Atar / Ministério da Saúde, Secretaria de Vigilância em Saúde, Departamento de DST, Aids e Hepatites Virais. - Brasília: Ministério da Saúde, 2010.

15. CARVALHO, Flávia Helena Pontes de et al. Co-infecção por HIV/HCV em hospital universitário de Recife, Brasil. Revista de Saúde Pública [online]. 2009, v. 43, n. 1 [Acessado 1 Setembro 2021], pp. 133-139.16.

16. FARIAS, Norma et al . Coinfecção pelos vírus das hepatites B ou C e da imunodeficiência adquirida: estudo exploratório no Estado de São Paulo, Brasil, 2007 a 2010. Epidemiol. Serv. Saúde, Brasília, v. 21, n. 3, p. 475-486, set. 2012.

17. PINTO, Agnes Caroline et al. Compreensão da pandemia da AIDS nos últimos 25 Anos. DST - J Bras Doenças Sex Transm. 2007;19(1):45-50.

18. SINGH, Sarman. Changing trends in the epidemiology, clinical presentation, and diagnosis of Leishmania-HIV co-infection in India, International Journal of Infectious Diseases. 2004. Volume 29.103-112.

19. BAUTISTA-AMOROCHO, Henry et al. Epidemiology, Risk Factors and Genotypes of HBV in HIV-Infected Patients in the Northeast Region of Colombia: High Prevalence of Occult Hepatitis B and F3 Subgenotype Dominance. Blackard J, ed. PLoS ONE. Dez. 2014.

20. SOUSA-GOMES, Marcia Leite de et al . Coinfecção Leishmania-HIV no Brasil: aspectos epidemiológicos, clínicos e laboratoriais. Epidemiol. Serv. Saúde, Brasília, v. 20, n. 4, p. 519-526, dez. 2011.

21. XAVIER, Graciela Augusto et al. Evaluation of seroepidemiological toxoplasmosis in HIV/AIDS patients in the south of Brazil. Revista do Instituto de Medicina Tropical de São Paulo [online]. 2013, v. 55, n. 1 [Accessed 1 September 2021] , pp. 25-30. 